\title{
Evaluating Team Performance Using Slack Based Data Envelopment Analysis
}

\author{
Chuen Tse Kuah*, Kuan Yew Wong* \\ *Department of Manufacturing and Industrial Engineering, Faculty of Mechanical Engineering, \\ Universiti Teknologi Malaysia, Skudai, Malaysia. \\ joseph.kuah84@gmail.com, wongky@fkm.utm.my
}

\begin{abstract}
The main objective of this paper is to devise a Data Envelopment Analysis (DEA) model to assess team performance. The DEA model in this study uses slack based measure (SBM), a method which deals directly with the input excesses and output shortfall. An explanatory example has been given to demonstrate the applicability of the model to evaluate team performance. From this study, it is found that DEA is suitable to measure team performance. The model is able to provide improvement targets to the inefficient teams. Lastly, a few directions for future research have been identified.
\end{abstract}

Keywords - Team performance evaluation, Data Envelopment Analysis (DEA), Slack Based Measure (SBM)

\section{INTRODUCTION}

Traditionally, employees have been evaluated and rewarded as individuals. This type of evaluation is still practiced in organizations where most work is still independently completed by different individuals. However, today's business environments have become much complex and dynamic which have been attributed to globalization and competitiveness of the global economy [1]. Complex and dynamic environments require fast and innovative responses [2]. To cope with these challenging environments, increased employee involvement is mandatory because these conditions require rapid decision making, flexible approaches, capitalintensive processes, and knowledge work [1]. Many mechanisms to increase employee involvement involve the creation of formal or informal teams to facilitate integration, coordination, and innovation [1].

In order to cope with increasing demands for faster product introduction and higher quality products and services, teams are formed. A team is a unit formed by two or more individuals who interact with each other dynamically, interdependently, and flexibly [3]. Team members share same valuable goals, objectives, tasks, and operating environments [4]. Teams can both be temporary and permanent. Temporary teams are formed to solve a particular problem and may be disbanded after they have achieved their objectives. Permanent teams are established to achieve long term objectives or solve long term problems.

Since many organizations have formed teams to accomplish complicated tasks more effectively and efficiently, it is important for such organizations to include team performance assessment in their appraisal system. Team performance can be viewed as the actual results of a team in achieving its targets [5].

Team performance evaluation has been extensively researched due to its importance on organizational performance. However, it remains to be a difficult area due to standardized measures are still lacking. Evaluation systems which indicate clearly which measures to consider and show how well the teams are performing are needed.

Performance measures or metrics are an important component of performance evaluation. Experts in the field of performance measurement have proposed an array of possible measures. However, these measures have to be evaluated before adopted for team evaluation. In addition, it is hard, if not impossible, to propose a universal set of measures for all organizations to evaluate their teams due to the differences between the organizations. For instance, a manufacturing firm's and an accounting firm's measurements would be fundamentally different. Therefore, care must be taken in deciding a set of performance measures to be implemented in an organization.

Furthermore, a sound team performance evaluation has to ensure that all the important elements must be measured to get a true picture of a team's performance. However, due to the interdependencies between the measures, it would be very difficult to establish explicit relationships between them.

Another important feature of performance evaluation is providing feedback to the teams so that the teams would not only know their performance levels but also have an idea on which areas they should improve on.

The major objective of this paper is to propose a method to measure team performance based on Data Envelopment Analysis (DEA). In this paper, team performance is evaluated as a process which converts multiple inputs into multiple outputs. A productivity approach is use where the performance is measured by a weighted ratio of the outputs to the inputs. To ensure fairness in the evaluation, DEA is used to devise the team performance evaluation model. DEA is a mathematical model which determines the set of weights for the measures which would optimize the performance score of a decision making unit (DMU) under evaluation while comparing it relatively with the other DMUs.

The rest of the paper is structured as follows. The next section gives a review on the topic of team performance evaluation. Following this, the developed model will be 
explained. Then, an application of the model on research and development teams is demonstrated using experimental data. Finally, the paper ends by giving conclusions of the study and a few future research directions.

\section{A ReView on Team Performance EVAluation}

A team is composed of individuals, often having heterogeneous knowledge, skills, and attitudes, working interdependently to achieve a shared goal [6]. The term team performance embodies teamwork, which can be understood as the behavioral, cognitive, and affective processes that teams possess in order to coordinate their interactions towards shared goals [7]. To achieve these goals, they have to coordinate, communicate, and cooperate [8]. Thus, team performance evaluation can be defined as the application of standardized evaluation tools to assess the goal achievements of teams in relation to the resources given.

Team performance evaluation can be used for multiple purposes. First, it can be used to guide learning through a systematic, developmental feedback [9]. Second, it provides a snapshot of team development. This allows management to have a clear picture on the current performance of its teams. Third, it can be used to validate the effectiveness of team trainings [9]. Fourth, it provides a guide to reward groups for good performance and encourage the organization to move towards a more team-focused environment [10]. Performance measurement contributes towards team success and it is necessary if members are to be rewarded for team performance [2].

Due to its importance, team performance evaluation has been widely researched and there are a number of team performance measurement models. Reference [11] reviewed about 130 models and frameworks of team performance. Among these different models and frameworks, the dominant framework is the input-process-output (IPO) framework, which originates from the general system theory and its many derivatives [11]. IPO models emphasize the importance of throughputs as mediators or moderators of the relations between input and output measures and they have advanced the collective understanding of the factors that constitute team performance [11].

Multiple measures have to be employed for performance evaluation [12]. Financial measures alone are not sufficient as they fail to capture critical aspects of performance and are not timely enough [13]. Scott and Tiessen found that teams that use comprehensive performance measurement, with both financial and non-financial measures, and encourage team members to participate in developing performance targets, perform better than those that do not [2]. Therefore, the measures should include not only the financial components, but also the other components such as quality, operational and cognitive elements. In addition, the measures used should be able to capture both the inputs and outputs of the teams. As mentioned earlier, a universal set of measures that can fit all organizations is not available. For a list of most commonly used measures, readers can refer to Scott and Tiessen [2]. An organization should increase the participation of its team members in developing a set of measures that is suitable for the organization based on its business nature.

Taking the approach of the IPO framework, this study developed a team performance evaluation model based on DEA. This will be explained in the following section.

\section{DEA Model for Team Performance Evaluation}

Taking the approach of the IPO framework, this study developed a team performance evaluation model based on DEA. This section will firstly present the conceptual model and the performance measures involved. Then, the developed DEA model will be described.

\section{A. Conceptual Model for Team Performance Evaluation}

In this study, a team is viewed as a DMU or process which converts multiple inputs into multiple outputs. In other words, this is an adaptation of the IPO framework. Figure 1 shows the conceptual model for this IPO concept.

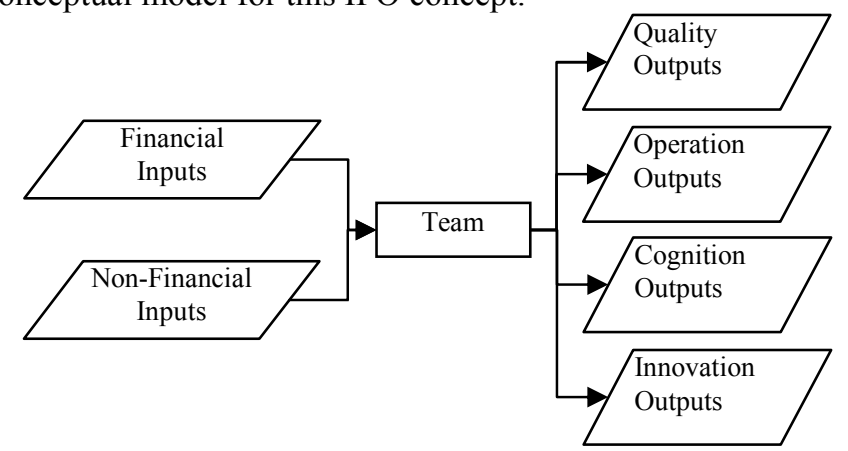

Figure 1. Team as DMU

The inputs or enablers are categorized into financial and non-financial inputs; while the outputs or results are categorized into quality, operation, cognition, and innovation outputs.

Tables 1 and 2 show the input and output measures proposed in this study. An explanation on the measures is given next. It has to be noted that this list is by no means to be an exclusive or universal list for evaluation of teams in any organization because as mentioned earlier, an organization has to develop a set of measures based on its business nature.

TABLE 1. INPUT MEASURES OF TEAM PERFORMANCE

\begin{tabular}{|c|l|l|l|}
\hline Symbols & \multicolumn{1}{|c|}{ Inputs } & \multicolumn{1}{c|}{ Units } & Categories \\
\hline$x_{1}$ & $\begin{array}{l}\text { Number of team } \\
\text { members }\end{array}$ & $\begin{array}{l}\text { Number of } \\
\text { members }\end{array}$ & Non-financial \\
\hline$x_{2}$ & $\begin{array}{l}\text { Monthly number of } \\
\text { hours of team meetings }\end{array}$ & Hour & Non-financial \\
\hline$x_{3}$ & $\begin{array}{l}\text { Monthly expenditure } \\
\text { on team trainings }\end{array}$ & USD & Financial \\
\hline$x_{4}$ & $\begin{array}{l}\text { Monthly investment in } \\
\text { supportive technologies }\end{array}$ & USD & Financial \\
\hline
\end{tabular}


TABLE 2. OUTPUT MEASURES OF TEAM PERFORMANCE

\begin{tabular}{|c|l|l|l|}
\hline Symbols & \multicolumn{1}{|c|}{ Outputs } & \multicolumn{1}{c|}{ Units } & Categories \\
\hline$y_{1}$ & $\begin{array}{l}\text { Percentage of quality } \\
\text { products }\end{array}$ & $\%$ & Quality \\
\hline$y_{2}$ & $\begin{array}{l}\text { Percentage of } \\
\text { satisfied customers }\end{array}$ & $\%$ & Quality \\
\hline$y_{3}$ & $\begin{array}{l}\text { Percentage of on- } \\
\text { time deliveries }\end{array}$ & $\%$ & Operation \\
\hline$y_{4}$ & $\begin{array}{l}\text { Estimated monthly } \\
\text { number of } \\
\text { communications } \\
\text { between members }\end{array}$ & $\begin{array}{l}\text { Number of } \\
\text { communications }\end{array}$ & Cognition \\
\hline$y_{5}$ & $\begin{array}{l}\text { Monthly number of } \\
\text { new ideas, } \\
\text { knowledge, and } \\
\text { solutions generated }\end{array}$ & $\begin{array}{l}\text { Number of } \\
\text { ideas, } \\
\text { knowledge, and } \\
\text { solutions }\end{array}$ & Innovation \\
\hline$y_{6}$ & $\begin{array}{l}\text { Monthly number of } \\
\text { new products or } \\
\text { services generated }\end{array}$ & $\begin{array}{l}\text { Number of } \\
\text { products or } \\
\text { services }\end{array}$ & Innovation \\
\hline
\end{tabular}

1) Input measures: The first input, $x_{1}$, is the number of team members, which is a non-financial measure. Team members are the fundamental building block of a team. They possess different skills and knowledge, collaborate and work together to achieve common goals and objectives. A team with more members is assumed to consume more resources and therefore is expected to produce more outputs.

The second input, $x_{2}$, is the monthly number of hours of team meetings, which is also a non-financial measure. Team meetings can have the objectives of information dissemination, idea generation, general discussion, troubleshooting, etc. The number of hours is chosen instead of the number of monthly meetings because the former represents the consumed resources more accurately.

The third input, $x_{3}$, is the monthly expenditure on team trainings. This is a financial or monetary measure. Team trainings can be conducted by internal or external experts. They can be trainings on specific new knowledge or technologies or even team building activities. These trainings are means to transfer up-to-date knowledge to team members and foster a closer relationship between members and thus enhance team performance and teamwork.

The fourth input, $x_{4}$, is the monthly investment in supportive technologies, which is also a financial measure. Supportive technologies support team performance in various ways. These technologies include displays and tools to support shared situation awareness, groupware, task tracking and reporting systems, etc.

2) Output measures: The first output, $y_{1}$, is the percentage of quality products. This is grouped under the category of quality output. Quality products are measured by the total number of units produced minus defective, reworked, and scrapped units.

The second output, $y_{2}$, which is also in the category of quality output, is the percentage of satisfied customers. It can be a measure of the number of sales or number of customers served minus the number of complaints received.

The third output, $y_{3}$, is the percentage of on-time deliveries, which is an operation output measure. On-time delivery is widely used to measure the fulfillment of a customer's demand on the pre-agreed delivery date.

The fourth output, $y_{4}$, is set as the estimated monthly number of communications between members. Communications between employees such as emails and phone calls are a way to convey information and share knowledge and it is a cognitive process. It is a central catalyst of information processing and knowledge sharing. Furthermore, more communications also represent better relationships between the members.

The fifth output, $y_{5}$, is the monthly number of new ideas, knowledge, and solutions generated, which is categorized as an innovation output. This is a suitable measure to gauge how innovative the members are. The more they interact and synergize their knowledge, the better they will perform in this measurement.

The sixth output, $y_{6}$, is the monthly number of new products or services generated, which is also an innovation output. In the fast-paced, challenging, and knowledge-intensive environment, one of the ways that organizations can use to increase their customers is by introducing innovative products or services. Thus, this has been recognized as one of the measures for team performance as well.

\section{B. DEA Modeling for Team Performance Evaluation}

For the purpose of consolidating all the measures into a single score which can be easily interpreted by managers and team leaders, DEA is employed. DEA is a mathematical programming technique proposed by Charnes, Cooper, and Rhodes [14]. It compares the measures objectively and relatively between the DMUs (in this case, the teams) under evaluation and determines the optimum set of weights that yields the highest possible performance score for each DMU. DEA is identified to be a suitable tool in evaluating team performance because it can handle multiple inputs and outputs and it does not require prior assumptions on the weights.

A DMU's efficiency is calculated by comparing with all the DMUs under evaluation. The calculation of the performance score in DEA adheres to the traditional productivity performance evaluation approach which obtains the score from the weighted sum of outputs divided by the weighted sum of inputs. However, the set of weights for a DMU is computed in DEA with the objective to give the highest possible relative efficiency score for the DMU, while keeping the efficiency scores of other DMUs in the range of 0 to 1 under the same set of weights [15]. Generally, efficient DMUs obtain a score of 1 while inefficient ones obtain a score of less than 1 .

There are a number of extensions and variations of DEA models. The DEA model chosen for this study uses the slack based measure (SBM) which was introduced by Tone [16]. SBM is chosen because it is able to deal directly with the input excesses and the output shortfalls of the DMU under evaluation, it is invariant to the units of measurement, and it is monotone decreasing with respect to each input and output slack [15]. The model is described as follows.

Consider there are $n$ DMUs: $\mathrm{DMU}_{1}, \mathrm{DMU}_{2}, \ldots$, and $\mathrm{DMU}_{n}$. Each $\mathrm{DMU}_{j},(j=1,2, \ldots, n)$ uses $m$ inputs $x_{i j}(i=1, \ldots, m)$ and 
generates $s$ outputs $y_{r j}(r=1, \ldots, s)$. Let the input slacks (surpluses) be $s_{i}^{-}(i=1, \ldots, m)$ and the output slacks (shortfalls) be $s_{r}{ }^{+}(r=1, \ldots, s)$. Let the $\mathrm{DMU}_{j}$ to be evaluated on any trial be designated as $\mathrm{DMU}_{0}(0=1,2, \ldots, n)$. The performance score $E_{0}$ of each $\mathrm{DMU}_{0}$ is found by solving the SBM model shown in Model (1) [15].

$$
\min E_{0}=\frac{1-\frac{1}{m} \sum^{i} \frac{s_{i}^{-}}{x_{i 0}}}{1+\frac{1}{s} \sum_{r} \frac{s_{r}^{+}}{y_{r 0}}}
$$

s.t. $\sum_{j} \lambda_{j} x_{i j}+s_{i}^{-}=x_{i 0}$

$\sum_{j} \lambda_{j} y_{r j}-s_{r}^{+}=y_{r 0}$

$\sum_{j} \lambda_{j}=1$

$\lambda_{j}, s_{i}^{-}, s_{r}^{+} \geq 0$

where $\lambda$ is a nonnegative vector of weights for the inputs and outputs. The highest score a DMU can obtain is 1 , which is only achievable when all slacks are equal to zero. Similar to traditional DEA models, a DMU is considered as efficient only if it gets an efficiency score of 1 ; else it is considered as inefficient. Next, to provide feedback to the inefficient teams on how much improvement they should achieve in their measurements, improvement targets are calculated through an operation called SBM-projection. This is done by subtracting the input excess and augmenting the output shortage as shown in Model (2). For $r=1,2$, and 3, the improvement targets are limited to be within 100 because the unit for $y_{1}, y_{2}$, and $y_{3}$ is percentage, thus cannot be more than 100 . These improvement targets can be used by teams to devise plans to shift themselves to the efficient frontier.

$$
\begin{aligned}
& x_{i 0}^{*}=x_{i 0}-s_{i 0}{ }^{-} \\
& y_{r 0}^{*}=\left\{\begin{array}{c}
y_{r 0}+s_{r 0}{ }^{+}, y_{r 0}^{*} \leq 100, \text { for } r=1,2,3 \\
y_{r 0}+s_{r 0}{ }^{+}, \text {for } r=4,5,6
\end{array}\right.
\end{aligned}
$$

To demonstrate the applicability of the model, an illustrative example will be shown next.

\section{AN ILLUSTRATIVE EXAMPLE}

A total of 40 research and development teams or DMUs have been included in this example. Table 3 shows the data set for the 40 DMUs.

A simple program was written using Microsoft Excel to solve Model (1) based on the data set. The results are shown in Table 4. Also included in Table 4 are the slacks (surpluses and shortages) and the ranking of the DMUs according to their

\begin{tabular}{|c|c|c|c|c|c|c|c|c|c|c|}
\hline DMU & $x_{1}$ & $x_{2}$ & $x_{3}$ & $x_{4}$ & $y_{1}$ & $y_{2}$ & $y_{3}$ & $y_{4}$ & $y_{5}$ & $y_{6}$ \\
\hline 1 & 27 & 18 & 4900 & 1400 & 97 & 96 & 96 & 900 & 7 & 0 \\
\hline 2 & 11 & 29 & 1900 & 1400 & 97 & 87 & 88 & 800 & 5 & 2 \\
\hline 3 & 23 & 17 & 2000 & 2200 & 90 & 86 & 88 & 1300 & 9 & 2 \\
\hline 4 & 16 & 30 & 4500 & 2200 & 94 & 93 & 90 & 1500 & 7 & 0 \\
\hline 5 & 23 & 17 & 1200 & 1300 & 95 & 98 & 97 & 1700 & 9 & 0 \\
\hline 6 & 12 & 30 & 3000 & 1800 & 88 & 93 & 92 & 1000 & 7 & 2 \\
\hline 7 & 16 & 28 & 4400 & 2000 & 86 & 89 & 88 & 2600 & 6 & 1 \\
\hline 8 & 16 & 34 & 2900 & 1700 & 98 & 88 & 93 & 900 & 9 & 1 \\
\hline 9 & 18 & 21 & 3900 & 1600 & 99 & 92 & 96 & 4000 & 9 & 2 \\
\hline 10 & 24 & 23 & 2700 & 2500 & 99 & 97 & 90 & 3200 & 6 & 2 \\
\hline 11 & 15 & 22 & 3200 & 1500 & 92 & 98 & 91 & 3100 & 7 & 0 \\
\hline 12 & 24 & 13 & 3100 & 2000 & 86 & 90 & 96 & 2800 & 9 & 0 \\
\hline 13 & 27 & 6 & 1000 & 2500 & 86 & 86 & 98 & 3500 & 7 & 0 \\
\hline 14 & 23 & 32 & 4000 & 1800 & 90 & 85 & 97 & 2000 & 9 & 0 \\
\hline 15 & 5 & 8 & 2100 & 1700 & 91 & 89 & 89 & 3100 & 8 & 2 \\
\hline 16 & 15 & 8 & 3200 & 1200 & 88 & 86 & 98 & 1900 & 8 & 1 \\
\hline 17 & 5 & 26 & 2500 & 1200 & 97 & 91 & 98 & 900 & 8 & 1 \\
\hline 18 & 28 & 12 & 4000 & 1900 & 95 & 96 & 89 & 2800 & 8 & 1 \\
\hline 19 & 17 & 27 & 3300 & 1200 & 92 & 94 & 87 & 2300 & 8 & 0 \\
\hline 20 & 19 & 8 & 2700 & 1900 & 96 & 88 & 91 & 1600 & 7 & 0 \\
\hline 21 & 12 & 28 & 2300 & 2100 & 86 & 90 & 85 & 2700 & 7 & 1 \\
\hline 22 & 11 & 19 & 3500 & 1500 & 93 & 88 & 86 & 1400 & 9 & 1 \\
\hline 23 & 15 & 28 & 1100 & 1300 & 96 & 96 & 91 & 3800 & 9 & 1 \\
\hline 24 & 19 & 20 & 4700 & 1400 & 95 & 88 & 99 & 3100 & 6 & 0 \\
\hline 25 & 26 & 29 & 4200 & 2500 & 93 & 98 & 95 & 1700 & 6 & 2 \\
\hline 26 & 5 & 30 & 3700 & 1800 & 87 & 85 & 94 & 1800 & 8 & 1 \\
\hline 27 & 5 & 29 & 2400 & 1400 & 88 & 92 & 96 & 2600 & 8 & 0 \\
\hline 28 & 25 & 16 & 3800 & 1700 & 85 & 95 & 86 & 1900 & 5 & 2 \\
\hline 29 & 26 & 30 & 2600 & 2100 & 88 & 85 & 88 & 900 & 9 & 2 \\
\hline 30 & 25 & 29 & 2200 & 1400 & 91 & 97 & 97 & 1300 & 8 & 0 \\
\hline 31 & 9 & 26 & 3300 & 1700 & 88 & 86 & 96 & 2700 & 6 & 0 \\
\hline 32 & 17 & 20 & 1600 & 1300 & 97 & 90 & 87 & 1200 & 9 & 0 \\
\hline 33 & 19 & 29 & 2600 & 1300 & 90 & 86 & 92 & 3800 & 8 & 0 \\
\hline 34 & 9 & 32 & 2000 & 2400 & 90 & 98 & 99 & 2600 & 5 & 2 \\
\hline 35 & 25 & 17 & 2900 & 1400 & 98 & 96 & 95 & 3000 & 10 & 2 \\
\hline 36 & 24 & 23 & 5000 & 2500 & 85 & 93 & 99 & 3700 & 10 & 2 \\
\hline 37 & 8 & 25 & 1700 & 2000 & 97 & 85 & 97 & 2900 & 8 & 1 \\
\hline 38 & 22 & 8 & 1000 & 1400 & 85 & 89 & 86 & 3500 & 10 & 1 \\
\hline 39 & 8 & 16 & 4500 & 1700 & 88 & 97 & 88 & 3700 & 8 & 2 \\
\hline 40 & 28 & 35 & 4200 & 1200 & 92 & 87 & 96 & 2600 & 9 & 2 \\
\hline
\end{tabular}
performance scores.
TABLE 3. DATA SET

From the analysis, there are 19 efficient DMUs and 21 inefficient ones. Slacks in Table 4 represent the input excesses and the output shortfalls respectively. To become efficient, a DMU has to remove the input excesses and augment the output shortfalls. For those inefficient DMUs, Model (2) has been run to obtain the improvement targets for them. The improvement targets are recorded in Table 5.

The improvement targets provide the teams with a direction and focus on which measures they should reduce or increase. Take $\mathrm{DMU}_{1}$ as an example, to become efficient, it should reduce its number of team members $\left(x_{1}\right)$ from 27 to 17 , monthly number of hours of team meetings $\left(x_{2}\right)$ from 18 to 9 , monthly expenditure on team trainings $\left(x_{3}\right)$ from 4900 to 3029 ; increase its percentage of on-time deliveries $\left(y_{3}\right)$ from $96 \%$ to $100 \%$, estimated monthly number of communications between members $\left(y_{4}\right)$ from 900 to 2502 , monthly number of new ideas, knowledge, and solutions generated $\left(y_{5}\right)$ from 7 to 9 , monthly number of new products or services generated $\left(y_{6}\right)$ from 0 to 1 ; and maintain its monthly investment in supportive technologies $\left(x_{4}\right)$ at 1400 , percentage of quality products $\left(y_{1}\right)$ at $97 \%$, and percentage of satisfied customers $\left(y_{2}\right)$ at $96 \%$. 
TABLE 4. Performance Score, Ranking, AND Slacks of DMUS

\begin{tabular}{|c|c|c|c|c|c|c|c|c|c|c|c|c|}
\hline$\vec{i}$ & 苛 & 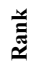 & $s_{1}{ }^{-}$ & $s_{2}^{-}$ & $s_{3}{ }^{-}$ & $s_{4}^{-}$ & $s_{1}^{+}$ & $s_{2}^{+}$ & $s_{3}{ }^{+}$ & $s_{4}^{+}$ & $s_{5}^{+}$ & $s_{6}^{+}$ \\
\hline 1 & 0.3920 & 34 & 10 & 9 & 1871 & 0 & 0 & 0 & 10 & 1602 & 2 & 1 \\
\hline 2 & 1 & 1 & 0 & 0 & 0 & 0 & 0 & 0 & 0 & 0 & 0 & 0 \\
\hline 3 & 1 & 1 & 0 & 0 & 0 & 0 & 0 & 0 & 0 & 0 & 0 & 0 \\
\hline 4 & 0.2462 & 40 & 11 & 22 & 2306 & 424 & 1 & 0 & 3 & 1739 & 1 & 2 \\
\hline 5 & 1 & 1 & 0 & 0 & 0 & 0 & 0 & 0 & 0 & 0 & 0 & 0 \\
\hline 6 & 0.4257 & 31 & 7 & 22 & 806 & 24 & 7 & 0 & 1 & 2239 & 1 & 0 \\
\hline 7 & 0.3803 & 35 & 11 & 20 & 2300 & 300 & 5 & 0 & 1 & 500 & 2 & 1 \\
\hline 8 & 0.4002 & 32 & 7 & 21 & 989 & 0 & 0 & 9 & 2 & 2620 & 0 & 1 \\
\hline 9 & 1 & 1 & 0 & 0 & 0 & 0 & 0 & 0 & 0 & 0 & 0 & 0 \\
\hline 10 & 0.4930 & 26 & 19 & 14 & 411 & 647 & 0 & 0 & 7 & 179 & 3 & 0 \\
\hline 11 & 0.5232 & 23 & 5 & 0 & 1346 & 0 & 8 & 0 & 6 & 0 & 2 & 1 \\
\hline 12 & 0.3577 & 37 & 18 & 4 & 738 & 88 & 16 & 10 & 4 & 687 & 0 & 2 \\
\hline 13 & 1 & 1 & 0 & 0 & 0 & 0 & 0 & 0 & 0 & 0 & 0 & 0 \\
\hline 14 & 0.2962 & 39 & 15 & 23 & 1823 & 0 & 8 & 12 & 0 & 1401 & 0 & 2 \\
\hline 15 & 1 & 1 & 0 & 0 & 0 & 0 & 0 & 0 & 0 & 0 & 0 & 0 \\
\hline 16 & 1 & 1 & 0 & 0 & 0 & 0 & 0 & 0 & 0 & 0 & 0 & 0 \\
\hline 17 & 1 & 1 & 0 & 0 & 0 & 0 & 0 & 0 & 0 & 0 & 0 & 0 \\
\hline 18 & 0.4859 & 28 & 23 & 3 & 1735 & 66 & 3 & 0 & 7 & 544 & 1 & 1 \\
\hline 19 & 1 & 1 & 0 & 0 & 0 & 0 & 0 & 0 & 0 & 0 & 0 & 0 \\
\hline 20 & 0.6335 & 22 & 1 & 0 & 265 & 0 & 0 & 7 & 14 & 1335 & 1 & 1 \\
\hline 21 & 0.4925 & 27 & 7 & 20 & 176 & 381 & 6 & 0 & 5 & 435 & 1 & 1 \\
\hline 22 & 0.6642 & 21 & 0 & 5 & 1560 & 0 & 2 & 5 & 8 & 1233 & 0 & 0 \\
\hline 23 & 1 & 1 & 0 & 0 & 0 & 0 & 0 & 0 & 0 & 0 & 0 & 0 \\
\hline 24 & 0.5157 & 24 & 5 & 2 & 2477 & 0 & 2 & 8 & 0 & 0 & 3 & 1 \\
\hline 25 & 0.3542 & 38 & 19 & 17 & 1112 & 0 & 41 & 33 & 36 & 2859 & 6 & 1 \\
\hline 26 & 0.6825 & 20 & 0 & 12 & 1378 & 378 & 7 & 5 & 0 & 78 & 0 & 0 \\
\hline 27 & 1 & 1 & 0 & 0 & 0 & 0 & 0 & 0 & 0 & 0 & 0 & 0 \\
\hline 28 & 0.5140 & 25 & 14 & 6 & 1552 & 0 & 11 & 0 & 8 & 1385 & 4 & 0 \\
\hline 29 & 0.3696 & 36 & 20 & 20 & 6 & 0 & 24 & 25 & 22 & 2929 & 1 & 0 \\
\hline 30 & 0.4473 & 29 & 9 & 0 & 1002 & 0 & 11 & 5 & 0 & 2733 & 2 & 1 \\
\hline 31 & 0.3924 & 33 & 4 & 14 & 997 & 0 & 10 & 9 & 0 & 144 & 2 & 2 \\
\hline 32 & 1 & 1 & 0 & 0 & 0 & 0 & 0 & 0 & 0 & 0 & 0 & 0 \\
\hline 33 & 1 & 1 & 0 & 0 & 0 & 0 & 0 & 0 & 0 & 0 & 0 & 0 \\
\hline 34 & 1 & 1 & 0 & 0 & 0 & 0 & 0 & 0 & 0 & 0 & 0 & 0 \\
\hline 35 & 1 & 1 & 0 & 0 & 0 & 0 & 0 & 0 & 0 & 0 & 0 & 0 \\
\hline 36 & 0.4465 & 30 & 17 & 11 & 1912 & 0 & 49 & 38 & 32 & 859 & 2 & 1 \\
\hline 37 & 1 & 1 & 0 & 0 & 0 & 0 & 0 & 0 & 0 & 0 & 0 & 0 \\
\hline 38 & 1 & 1 & 0 & 0 & 0 & 0 & 0 & 0 & 0 & 0 & 0 & 0 \\
\hline 39 & 1 & 1 & 0 & 0 & 0 & 0 & 0 & 0 & 0 & 0 & 0 & 0 \\
\hline 40 & 1 & 1 & 0 & 0 & 0 & 0 & 0 & 0 & 0 & 0 & 0 & 0 \\
\hline
\end{tabular}

TABLE 5. IMPROVEMENT TARGETS FOR INEFFICIENT DMUS

\begin{tabular}{|c|c|c|c|c|c|c|c|c|c|c|}
\hline DMU & $x^{*}{ }_{1}$ & $x^{*}{ }_{2}$ & $x^{*}{ }_{3}$ & $x^{*}{ }_{4}$ & $y^{*_{1}}$ & $y_{2}^{*}$ & $y^{*}{ }_{3}$ & $y^{*}{ }_{4}$ & $y^{*}{ }_{5}$ & $y^{*}{ }_{6}$ \\
\hline 1 & 17 & 9 & 3029 & 1400 & 97 & 96 & 100 & 2502 & 9 & 1 \\
\hline 2 & 5 & 8 & 2194 & 1776 & 95 & 93 & 93 & 3239 & 8 & 2 \\
\hline 4 & 5 & 8 & 2194 & 1776 & 95 & 93 & 93 & 3239 & 8 & 2 \\
\hline 9 & 5 & 8 & 2100 & 1700 & 91 & 89 & 89 & 3100 & 8 & 2 \\
\hline 10 & 9 & 13 & 1911 & 1700 & 98 & 97 & 95 & 3520 & 9 & 2 \\
\hline 12 & 5 & 9 & 2289 & 1853 & 99 & 97 & 97 & 3379 & 9 & 2 \\
\hline 13 & 10 & 22 & 1854 & 1500 & 100 & 98 & 97 & 3100 & 9 & 1 \\
\hline 17 & 6 & 9 & 2362 & 1912 & 100 & 100 & 100 & 3487 & 9 & 2 \\
\hline 19 & 8 & 9 & 2177 & 1800 & 98 & 97 & 97 & 3401 & 9 & 2 \\
\hline 21 & 5 & 9 & 2265 & 1834 & 98 & 96 & 96 & 3344 & 9 & 2 \\
\hline 22 & 18 & 8 & 2435 & 1900 & 96 & 95 & 100 & 2935 & 8 & 1 \\
\hline 24 & 5 & 8 & 2124 & 1719 & 92 & 90 & 90 & 3135 & 8 & 2 \\
\hline 26 & 11 & 14 & 1940 & 1500 & 95 & 93 & 94 & 2633 & 9 & 1 \\
\hline 28 & 14 & 18 & 2223 & 1400 & 97 & 96 & 99 & 3100 & 9 & 1 \\
\hline 31 & 7 & 12 & 3088 & 2500 & 100 & 100 & 100 & 4559 & 12 & 3 \\
\hline 33 & 5 & 18 & 2322 & 1422 & 94 & 90 & 94 & 1878 & 8 & 1 \\
\hline 34 & 11 & 10 & 2248 & 1700 & 96 & 95 & 94 & 3285 & 9 & 2 \\
\hline 35 & 6 & 10 & 2594 & 2100 & 100 & 100 & 100 & 3829 & 10 & 2 \\
\hline 36 & 16 & 29 & 1198 & 1400 & 100 & 100 & 97 & 4033 & 10 & 1 \\
\hline 37 & 5 & 12 & 2303 & 1700 & 98 & 95 & 96 & 2844 & 8 & 2 \\
\hline 38 & 7 & 12 & 3088 & 2500 & 100 & 100 & 100 & 4559 & 12 & 3 \\
\hline
\end{tabular}

\section{Conclusions}

As shown in the previous section, the developed model is applicable to evaluate team performance with minimum subjective judgment. It is able to consolidate the 10 performance measures into one performance score. The results could help the teams under evaluation to have an overview on how well they are performing in relation to each other. Furthermore, improvement targets are calculated for those inefficient teams, enabling them to know the specific measures they need to improve or maintain in order to become efficient.

A limitation of this study is all the measures are treated deterministically. However, in real life, measures like the estimated monthly number of communications between members $\left(y_{4}\right)$ are stochastic and hard to be determined accurately. Future work can look at how this issue can be addressed.

Lastly, while team evaluation in this study is not focused specifically on individuals, in future research, evaluation can be done in both team and member levels as to provide individualized feedback for individual members on how they could contribute more to improve their team performance.

\section{ACKNOWLEDGMENTS}

The authors would like to thank Universiti Teknologi Malaysia (Vote No: 03H22) and Ministry of Higher Education.

\section{REFERENCES}

[1] J. R. Galbraith and E. E. Lawler, Organizing for the Future, San Francisco: Jossey-Bass, 1993.

[2] T. W. Scott and P. Tiessen, "Performance measurement and managerial teams," Accounting, Organizations and Society, vol. 24, pp. 263-285, 1999

[3] R. W. Swezey and E. Salas, Teams: Their Training and Performance, Norwood: Ablex, 1992.

[4] Y. Zha, X. Ding, L. Liang, and Z. Huang, "A two-stage DEA approach with feed-back for team performance evaluation," Application of Management Science, vol. 15, pp. 3-18, 2012.

[5] M. T. Brannick, E. Salas, and C. Prince, Team Performance Assessment and Measurement: Theory, Methods, and Applications, Mahwah: Lawrence Erlbaum, 1997.

[6] P. Carayon, Handbook of Human Factors and Ergonomics in Health Care and Patient Safety, Mahwah: Lawrence Erlbaum, 2007.

[7] J. Mathieu, M. T. Maynard, T. Rapp, and L. Gilson, "Team effectiveness 1997-2007: A review of recent advancements and a glimpse into the future," Journal of Management, vol. 34, pp. 410-476, 2008.

[8] E. Salas, N. J. Cooke, and M. A. Rosen, "On teams, teamwork, and team performance: discoveries and developments," Human Factors, vol. 50, pp. 540-547, 2008.

[9] M. A. Rosen, S. J. Weaver, E. H. Lazzara, E. Salas, T. Wu, S. Silvestri, N. Schiebel, S. Almeida, and H. B. King, "Tools for evaluating team performance in simulation-based training," Journal of Emergency Trauma Shock, vol. 3, pp. 353-359, 2010.

[10] E. E. Lawler, Strategic Pay: Aligning Organizational Strategies and Pay Systems, San Francisco: Jossey-Bass, 1990.

[11] R. A. Dienstbier, J. W. Shuart, W. Spaulding, and J. Poland, Modeling Complex Systems: Motivation, Cognition and Social Processes: Nebraska Symposium on Motivation, Lincoln: University of Nebraska Press, 2007.

[12] R. S. Kaplan and D. P. Norton, "The balanced scorecard - measures that drive performance," Harvard Business Review, vol. 70, pp. 71-79, 1992. 
[13] G. Feltham and J. Xie, "Performance measure congruity and diversity in multi-task principal/agent relations," The Accounting Review, vol. 69, pp. 429-453, 1994

[14] A. Charnes, W. W. Cooper, and E. L. Rhodes, "Measuring the efficiency of decision making units," European Journal of Operational Research, vol. 2, pp. 429-444, 1978.

[15] C. T. Kuah, K. Y. Wong, and F. Behrouzi, "Application of data envelopment analysis to assess quality management efficiency," in Proc. 6th International Conference of the World Academy of Science, Engineering and Technology, 2010, paper 10, pp. 49-54

[16] K. Tone, "A slack-based measure of efficiency in data envelopment analysis," European Journal of Operational Research, vol. 130, pp. 498-500, 2001.
Chuen Tse Kuah is a PhD candidate at the Faculty of Mechanical Engineering, Universiti Teknologi Malaysia (UTM). His research interests include knowledge management, operations research, performance measurement, and Data Envelopment Analysis.

Kuan Yew Wong holds a PhD from the University of Birmingham, England. Currently, he heads the Industrial Engineering Laboratory at Universiti Teknologi Malaysia (UTM). He has been a Visiting Professor at the Faculty of Engineering, Autonomous University of the State of Mexico (UAEM) 